\title{
PROJETO DE EXTENSÃO UERJ NO CAMPO: DESENVOLVENDO O MEIO RURAL E A FORMAÇÃO DO PROFISSIONAL DE ENGENHARIA
}

DOI: 10.37702/2175-957X.COBENGE.2021.3425

Luiz Carlos Cordeiro Jr - luiz.cordeiro@fat.uerj.br

UERJ

Rua Benedito Alves de Moraes 157

27523-116 - Resende - RJ

Weslley Luis Manoel da Silva - wlmsilvauerj@gmail.com

UERJ

Rua Flack 75

20960-150 - Rio de Janeiro - RJ

Matheus lima da Silva - Matheuslima.uerj@gmail.com

Universidade do estado do rio de janeiro

Avenida nova resende 230

27542-130 - Resende - RJ

Resumo: Segundo Coralina, "Feliz aquele que transfere o que sabe e aprende o que ensina"; ou seja, a extensão universitária contribui na comunidade em geral ao propor que os alunos e a sociedade interajam e, desta forma, aja uma troca de valores entre ambos. "Nesse sentido, a relação entre o ensino e a extensão conduz a mudanças no processo pedagógico, na medida em que ambos constituem-se em sujeitos do mesmo ato: aprender". (Brasil, 2006). A UERJ, Universidade do Estado do Rio de Janeiro, estimula a participação do corpo docente e discente em diversas atividades em todos os campis, por meio de incentivos a eventos e estimulo ao desenvolvimento de projetos sociais através do apoio das unidades acadêmicas e mesmo de bolsas estudantis aos alunos para a realização destas atividades. A proposta a ser desenvolvida neste trabalho, iniciou antes do CNE/2019, e relata o grau de satisfação e maturidade que o projeto de extensão "UERJ no Campo", vem trazendo para os professores, alunos e voluntários, validando o potencial de que 0 ensino, pesquisa e extensão são atividades complementares no desenvolvimento acadêmico, ético e social na preparação do discente para o ingresso profissional a sociedade 


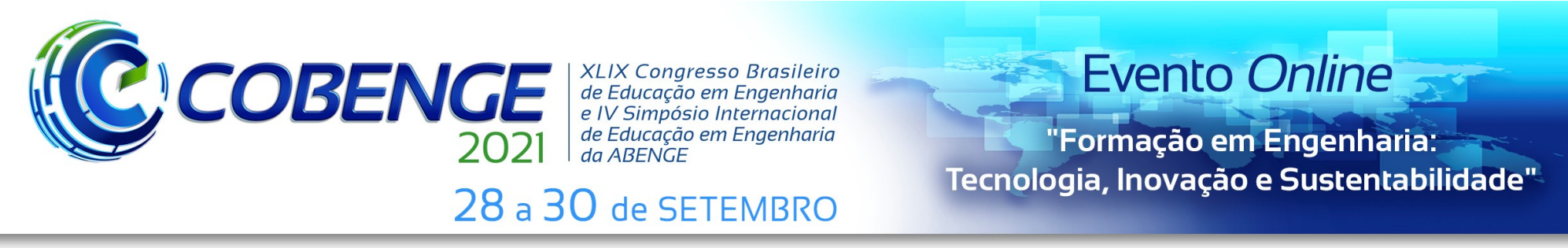

Palavras-chave: uerj no campo, extensão, atividade extensionista 


\section{PROJETO DE EXTENSÃO UERJ NO CAMPO: DESENVOLVENDO O MEIO RURAL E A FORMAÇÃO DO PROFISSIONAL DE ENGENHARIA}

\section{INTRODUÇÃO}

O desenvolvimento de atividade extensionistas, reflete um formato de relacionamento social entre as comunidades externas e as universidades. Os alunos deixam de seguir o ensino tradicional da sala de aula, e são introduzidos ao mundo real em que são motivados a reflexão dos problemas, a desenvolver soluções e se auto desenvolverem em valores éticos e profissionais, assim como desenvolver técnicas de empatia, comunicação, criatividade e empreendedorismo.

O objetivo inicial deste trabalho é descrever a experiência na aproximação junto a comunidade de agricultores locais, da região sul fluminense do Estado do Rio de Janeiro (Resende, Itatiaia e Porto Real) no compartilhamento de conhecimentos técnicos em diversas áreas do saber da engenharia. Esta aproximação somente foi possível com a ajuda de alunos, voluntários diversos, representantes dos agricultores, EMATER e do Sindicato Rural de Resende. Outro objetivo específico foi trabalhar com a própria formação extensionista do corpo docente e discente, visto nenhum dos participantes terem experiência em projetos sociais como este e em especial, durante plena pandemia. Porém, segundo Paulo Freire (1983), a extensão é estender algo a alguém, é um ser ativo, superior, messiânico dominador frente a um ser passivo e inferior. Ou em outras palavras, o processo extensionista promove a conscientização daquele que aprender e a autoconscientização daquele que ensina, é o desenvolvimento da maturidade do grupo e a percepção do quanto somos inferiores frente às questões sociais.

Nesta autoconscientização, é perceptível que o ganho de maturidade do aluno frente as ações extensionistas são um reflexo das competências desenvolvidas pelos integrantes do grupo, principalmente através dos processos de aprendizagem em metodologias ativas, como: aprendizado baseado em projetos e em problemas, despertando valores, competências e habilidades nos discentes envolvidos. (Silva, 2019)

\section{METODOLOGIA}

O Projeto "UERJ no Campo", possui como premissas a atuação extensionista no complemento do ensino acadêmico dos alunos de Engenharia Mecânica e de atender as necessidades técnicas dos produtores rurais, alinhados com a linha de conhecimento do corpo docente e demais voluntários ao projeto. As principais linhas de atuação do conhecimento do grupo estão apresentadas abaixo, e representam os pilares do desenvolvimento do grupo:

$\Rightarrow$ Hidráulica, análise do comprimento característico, estudo da perda de carga e levantamento de altura manométrica na correta especificação de bombas d'água para o meio rural, otimizando processos e recursos sendo desenvolvidas através de aulas, seminários e palestras. Assim como o estudo de possíveis ações alternativas, como desenvolvimento de bombas carneiro em material alternativo (PVC) e rodas d'água entre outras;

$\Rightarrow$ Coletores Solares, minimizar os custos operacionais, através do investimento na obtenção de água quente através de fonte renovável, é um dos pilares deste trabalho. Além da apresentação das técnicas e tecnologias existentes atualmente para coletores, assim como propostas de palestras e oficinas no desenvolvimento de modelos a partir de material reciclável; 
$\Rightarrow$ Propostas ergonômicas, focadas nas análises de processos e otimização de atividades, com objetivo de amenizar o impacto de movimentos repetitivos e melhora no processo produtivo. Assim como, as questões de saúde baseada nas questões de esforços, movimentos e postura na realização das atribuições operacionais e no manuseio de equipamentos;

$\Rightarrow$ Elétrica, orientar o manuseio junto a rede elétrica e ou equipamentos por intermédio dos devidos mecanismos de segurança e proteção é o objetivo desta atividade, evitando riscos desnecessários que protejam o produtor de exposição a acidentes elétricos e também ao risco de danificar equipamentos;

$\Rightarrow$ Refrigeração térmica passiva, buscar melhorias no bem estar térmico das pessoas, por intermédio do esclarecimento de benefícios simples e fáceis para serem implementados, sem a utilização de recursos ativos;

$\Rightarrow$ Controle de caixa, orientar o produtor a desenvolver controle de fluxo de caixa e planejamento financeiro são premissas que por mais simples possam ser, ainda não são praticadas por muitos produtores.

O desenvolvimento do projeto, acontece em um ambiente no qual o público alvo são os produtores rurais associados ao Sindicato Rural de Resende, em torno de 248 (duzentos e quarenta e oito) produtores, distribuídos em atividades, e também produtores que não estão associados, em torno de 794 (setecentos e noventa e quatro) que constam nos dados da EMATER em 2019, como mostrado na figura 1. O desenvolvimento do trabalho ocorre através de reuniões em plataformas virtuais junto aos produtores, professores, alunos. Embora que nem todos estes produtores dispõem de acesso à internet, frente as questões da pandemia causada pela Covid-19, ainda existe o auxílio da EMATER, contribuindo junto ao grupo através de vasta experiência de campo, no suporte na orientação das ações.

Figura 1 - Distribuição dos produtores nas cidades de Itatiaia, Porto Real e Resende

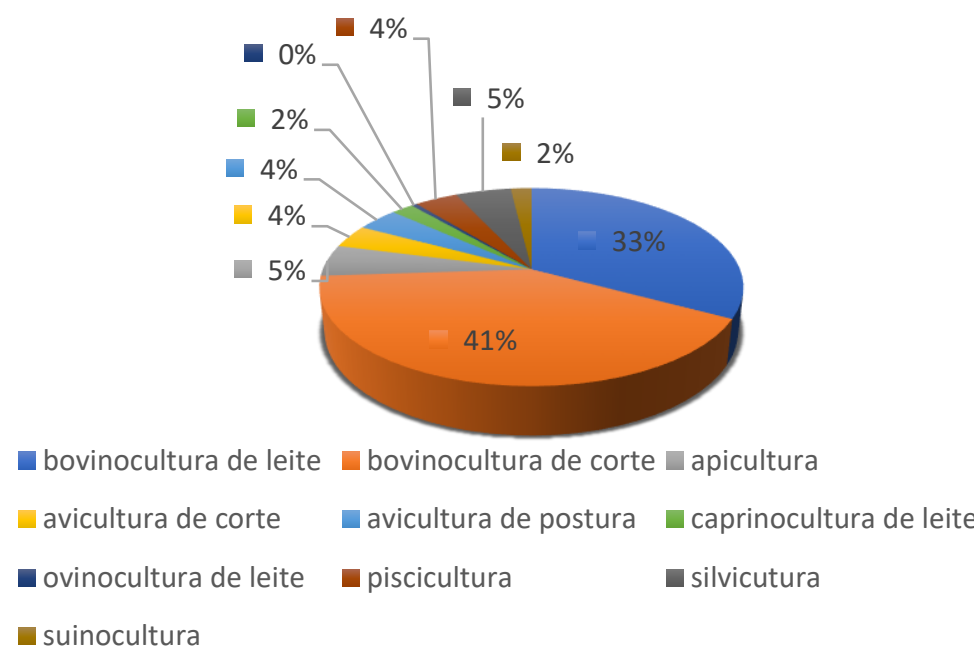

Fonte: EMATER- RIO (2019)

Os alunos, no desenvolvimento destas atividades extensionistas, frente as questões da pandemia causada pela COVID-19, são orientados pelos diversos professores a desenvolverem as linhas de pesquisa e desenvolvimento em ambiente seguro e dentro de protocolos de segurança e saúde. Destacam-se na condução das atividades a metodologia ativa, a qual propõe estimular os alunos para que aprendam de forma autônoma e participativa, a partir de problemas e situações reais. (Fonseca, 2007) 
Algumas das atividades realizadas nas ações extensionistas e que compõem a metodologia ativa a destacar foram: abordagem de problemas, desenvolvimento de projetos, cooperatividade, proatividade e estudo do meio (Silabe, 2021). O retrato social causado pela Covid-19, na questão de inter-relacionamento entre alunos e professores acelerou o uso de tecnologias e ferramentas ágeis virtuais, no qual a extensão teve que se adequar as plataformas virtuais, o que proporcionou o contínuo andamento da interatividade dos extensionistas com a sociedade sem interrupção das atividades, estimulando a autonomia, a autodisciplina e a maturidade. O grande impacto da extensão universitária na formação do engenheiro sobressai na aplicação da educação cognitiva que está conectada na construção do conhecimento, do pensamento crítico e reflexivo. (Portal Educação, 2021)

\subsection{Evolução do Projeto}

O crescimento do projeto dentro de dois anos, como mostrado na Figura 2. Reafirma o comprometimento da extensão com a população, através de medidas educativas para o desenvolvimento do meio rural. A união de mais voluntários proporciona diretamente a um aumento de sinergia e criatividade no desenvolvimento de atividades e no compartilhamento de informações e experiências.

Figura 2 - Aumento no número de integrantes na extensão

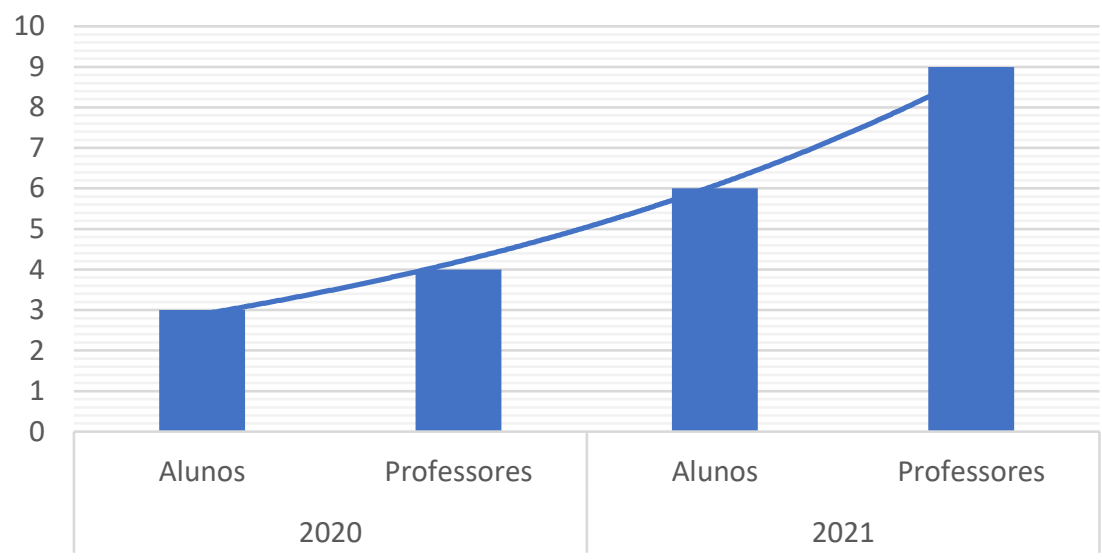

Fonte: O próprio autor (2021)

A evolução do projeto, conforme apresentada na figura anterior, foi marcada por dificuldades frente a pandemia COVID-19, a participação indicada neste gráfico reporta os participantes realmente ativos no projeto. Para os discentes participantes, foi marcado por um aprendizado de grande valor e oportunidades, frente a tantos professores e conhecimentos a disposição. Os alunos envolvidos no projeto, amadureceram em suas competências, 0 ato de praticar a empatia e se sensibilizar com as dificuldades operacionais das famílias na luta diária pela sobrevivência, desperta o sentimento de querer mudar, de evoluir para poder fazer algo. O amadurecimento, desperta a necessidade de competências, de valores e a percepção de que o dissente é necessário a sociedade, o qual ele faz parte. 


\subsection{Pesquisa para indicador de maturidade}

A pesquisa foi realizada com alunos que participam do projeto de extensão "UERJ no Campo", com o intuito de adquirir dados relevantes acerca das experiências obtidas, através dos seguintes tópicos listados: dificuldades encontradas ao ser integrado ao projeto, área de maior desenvolvimento pessoal e autoavaliação em relação aos valores de antes e depois de entrar no projeto de extensão.

Nos tópicos da pesquisa, foram levantados itens como: comunicação; relacionamento com os colegas de equipe; desenvolvimento de projetos; criatividade; comprometimento; empreendedorismo; empatia. Na primeira pergunta, a maior parte das respostas foram "Não teve dificuldades" (40\%) seguida por "desenvolvimento de projetos" (30\%). Enquanto outros itens ficaram menos relevantes com 10\%, como mostrado na Figura 3.

Figura 3 - Dificuldades encontradas ao ser integrado ao projeto

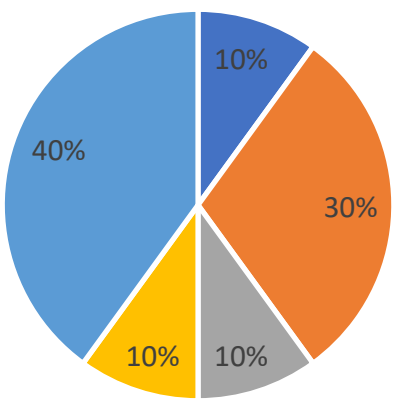

* comunicação

- desenvolvimento de projetos

criatividade

comprometimento

- Não teve dificuldades

Fonte: O próprio autor (2021)

O resultado da pesquisa acima, reflete um dado que se comparado com uma avaliação similar como exemplo (Castro Santos, 2020), 40\% dos alunos da UERJ não identificaram dificuldades frente ao desenvolvimento dos projetos. Este indicador é questionável, com base na dinâmica de realização das atividades deste projeto, este dado reflete a condição no qual os alunos não puderam se envolver totalmente ao projeto, na exposição direta junto aos produtores rurais, em virtude da restrição social devido a pandemia. A empatia desenvolvida, foi por intermédio de uma aproximação remota e não presencial, o que de certa forma atrapalhou no desenvolvimento das competências, porém, quando é comparado a questão de desenvolvimento de projetos, a comparação frente as dificuldades foram praticamente iguais entre os estudantes das Universidades "UNEF e UERJ", mesmo em decorrer de períodos diferentes.

Conforme abordado no trabalho de (Salles Cintra, 2019), em que descreve a promoção das competências dos alunos envolvidos nas atividades extensionistas, 0 gráfico 4, representa o ganho de competência dos alunos frente ao desenvolvimento de projetos, permitindo maior ganho de maturidade e autoconfiança frente aos desafios, característica marcante no autodesenvolvimento, fruto da junção ensino, pesquisa e extensão. Fator este que destaca ainda mais o perfil profissional destes alunos egressos frente ao mercado de trabalho, se destacando pelas competências desenvolvidas. Entretanto, a questão de relacionamento apresenta um indicador baixo, motivado a princípio pela restrição social e os desenvolvimentos das atividades na grande maioria de forma remota, o que diminui o vínculo na construção das afinidades entre os participantes 
Figura 4 - Área de maior desenvolvimento pessoal

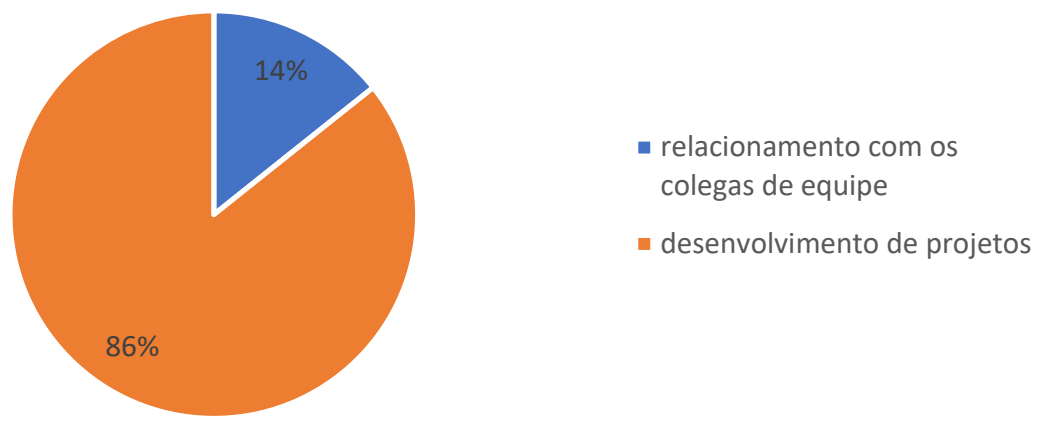

Fonte: O próprio autor (2021)

\subsection{Experimentos realizados}

O seguinte tópico tem como axioma, a tratativa de demonstrar os projetos já realizados e consequentemente sua funcionalidade para o setor rural. Dentre as conquistas neste projeto a serem pontuadas, destacam-se o desenvolvimento dos itens:

- Pluviômetro, para monitoramento local de pluviosidade na plantação de um referido agricultor;

- Coletor Solar, obtenção de água quente através de fontes renováveis, auxiliando na redução dos custos de processo;

- Totem solar, para aqueles que não dispõe de serventia de rede elétrica, a possibilidade de dispor de uma pequena fonte de energia fotovoltaica;

- Bomba carneiro, embora pouco eficiente, mas atrativa pelo baixo custo e recomendada para determinadas condições de abastecimento;

- Cálculo da altura manométrica, auxílio ao agricultor na correta especificação de uma bomba de água, através do suporte dos alunos;

- Aspersor, proposta de uso de um equipamento para prevenção ao Covid-19.

O primeiro projeto concluído foi o desenvolvimento de um pluviômetro de baixo custo feito de garrafa PET para medir a quantidade de chuva em milímetros de um determinado período de tempo, por meio deste é possível conhecer na agricultura o regime pluviométrico para ter noção de como e quando será a colheita, como mostrado na Figura 5.

Figura 5 - Pluviômetro de garrafa PET 


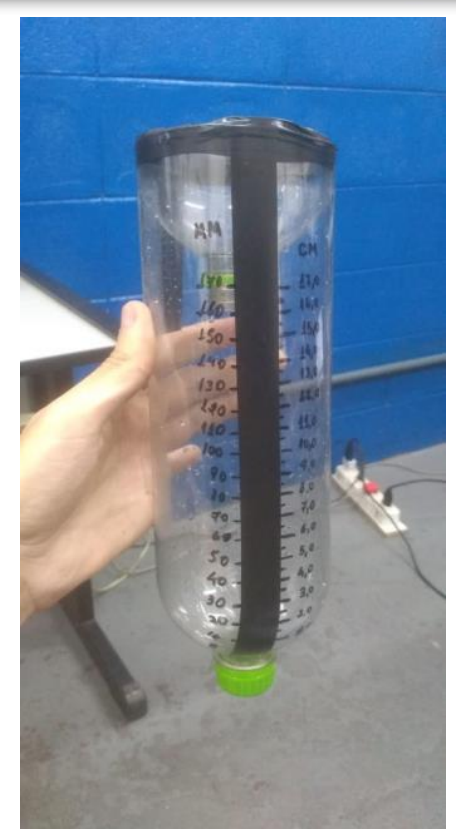

Fonte: O próprio autor (2021)

Outro projeto, foi o carneiro hidráulico, desenvolvido com os diâmetros de 3/4" e 1" possuem como finalidade bombear água sem uso da eletricidade e ou combustível, apenas com a força da gravidade, através do Golpe de Aríete, como observa-se na Figura 6. Essa bomba tem baixo custo e fabricação caseira, indicada para pequenos produtores rurais devido seu baixo rendimento. Normalmente é utilizada no abastecimento de bebedouro para animais ou em uma pequena área de irrigação, deve-se lembrar que necessita de condições favoráveis para utilização.

Figura 6 - Bomba carneiro de PVC

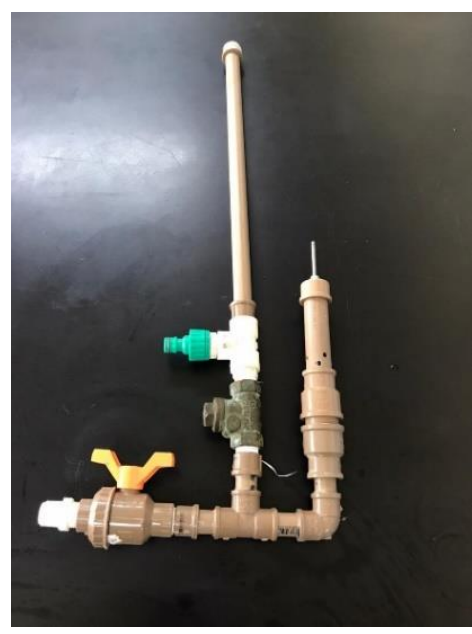

Fonte: O próprio autor (2021)

A construção de um coletor solar itinerante tornou-se necessária, logo após os produtores apontarem a necessidade diária do uso de água quente, devido o alto custo resulta em um aumento significante nos custos operacionais. Outrossim, o desenvolvimento de um coletor solar que acarretaria na melhora econômica do produtor por ser um material que utiliza energia renovável é essencial, como demonstrado na Figura 7. 
Figura 7 - Coletor Solar Itinerante

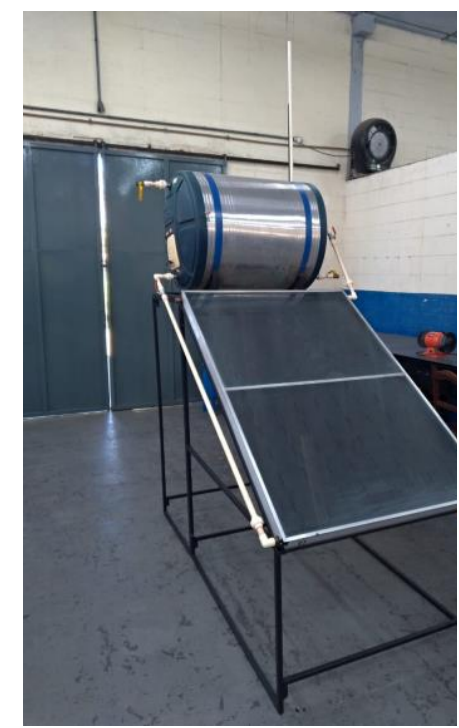

Fonte: O autor

Para os produtores geograficamente das cidades, necessidade para estes a principalmente em casos de apenas para contato. Porém, de uma rede elétrica nas sistema com baixa necessário dispor de uma com o intuito de recarregar as como celulares e outros

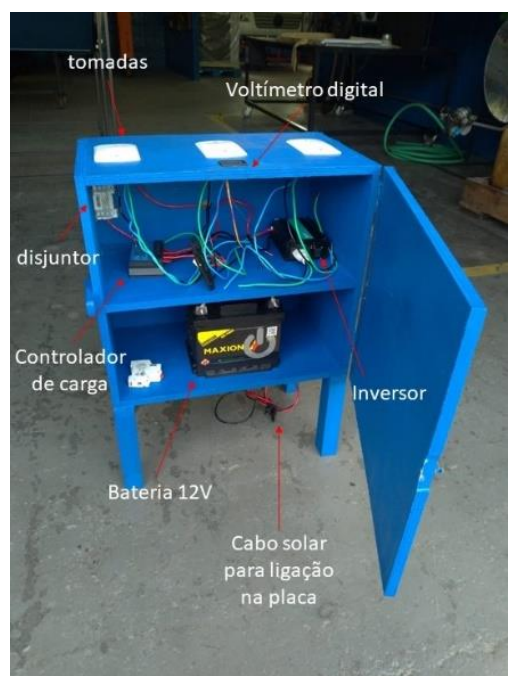

próprio (2021)

mais afastados foi identificado uma grande questão de comunicação, emergência, segurança ou quando não existe o suporte propriedades e ou um estabilidade, faz se fonte de segurança confiável, baterias de equipamentos meios de comunicação. Com o objetivo de amenizar esses problemas, o projeto de extensão "UERJ no Campo"
elaborou um totem que a partir de uma placa fotovoltaica é capaz de carregar a bateria de pequenos equipamentos como celulares, notebooks, entre outros, como demonstrado na Figura 8.

Figura 8 - Totem solar itinerante

\section{Proposta}

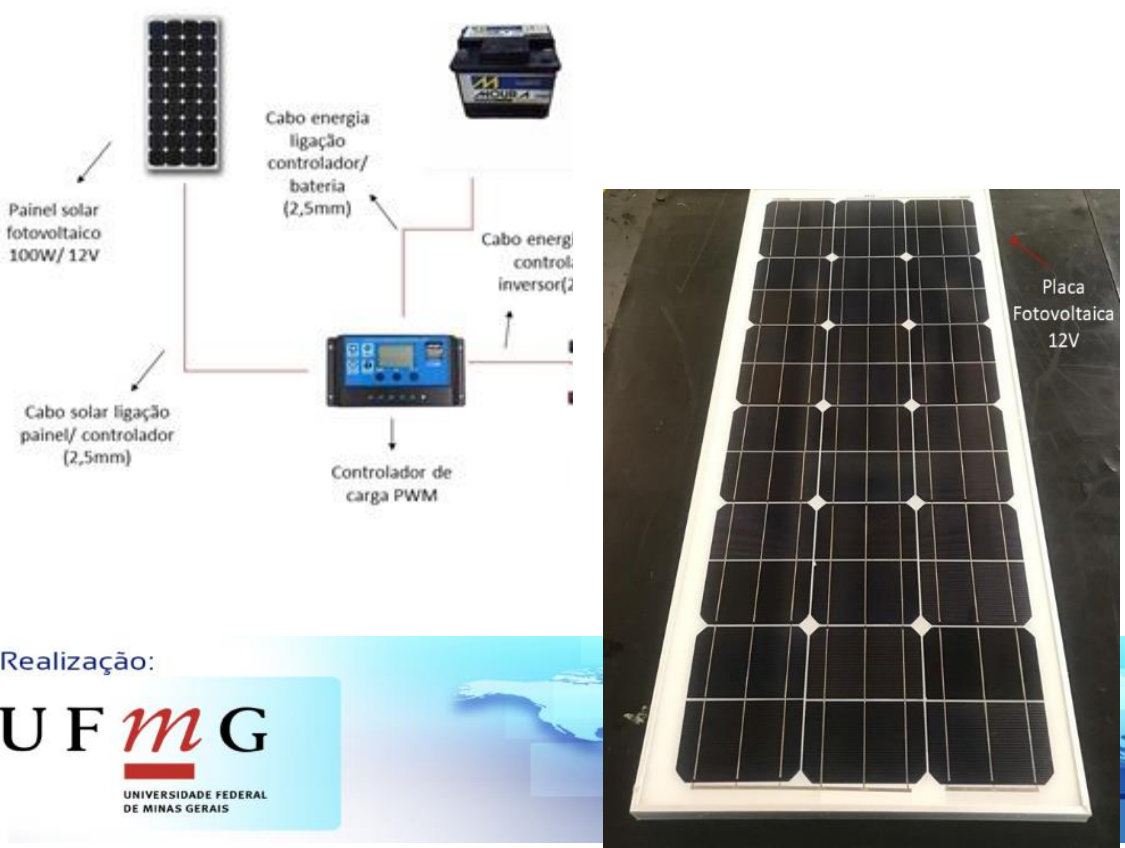


Fonte: O próprio autor (2021)

O Totem foi desenvolvido pelos alunos integrados ao projeto, e assim como o Coletor Solar, será da forma itinerante. Este modo, prevê a adoção do equipamento pelo produtor em um determinado tempo por meio de um contrato comodato, desta forma, ele será capaz de observar os possíveis ganhos através da experiência obtida.

O material a seguir, na Figura 9, refere-se a uma bancada hidráulica de baixa pressão, desenvolvida em pvc ou em aço galvanizado e servirá como suporte para a realização de oficinas junto aos produtores no auxílio ao procedimento da correta especificação de uma bomba de água, a partir do correto mapeamento da altura manométrica do sistema.

Figura 9 - Bancada para o cálculo da altura manométrica

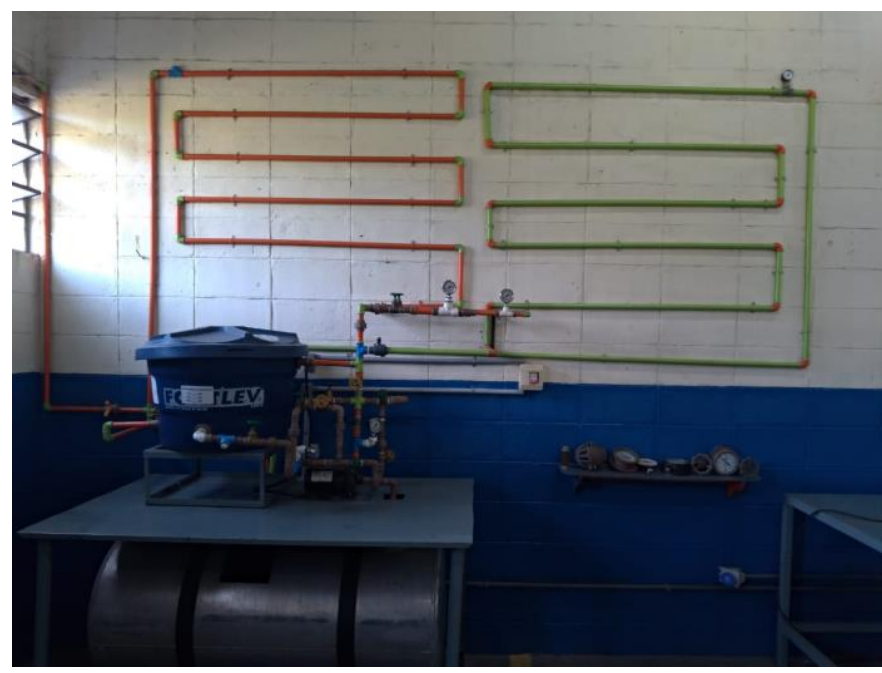

Fonte: O próprio autor (2021)

Conseguinte ao aparecimento do Covid-19, o projeto de extensão procura auxiliar a sociedade através do desenvolvimento de um equipamento para higienização e, desta forma, previna contra o vírus (Figura 10). O funcionamento ocorre por meio de um sensor de movimento (destacado de amarelo na figura 10) que através de aproximação aciona a bomba de água (abaixo do sensor de movimento) que bombeia toda a solução; o fluído presente vai de acordo com a necessidade podendo ser água oxigenada diluída ou hipoclorito de sódio; contida no balde por toda a tubulação de pvc, neste momento os aspersores de irrigação (destacados de vermelho) acionam e realizam a umidificação.

Figura 10 - Aspersor para higienização 


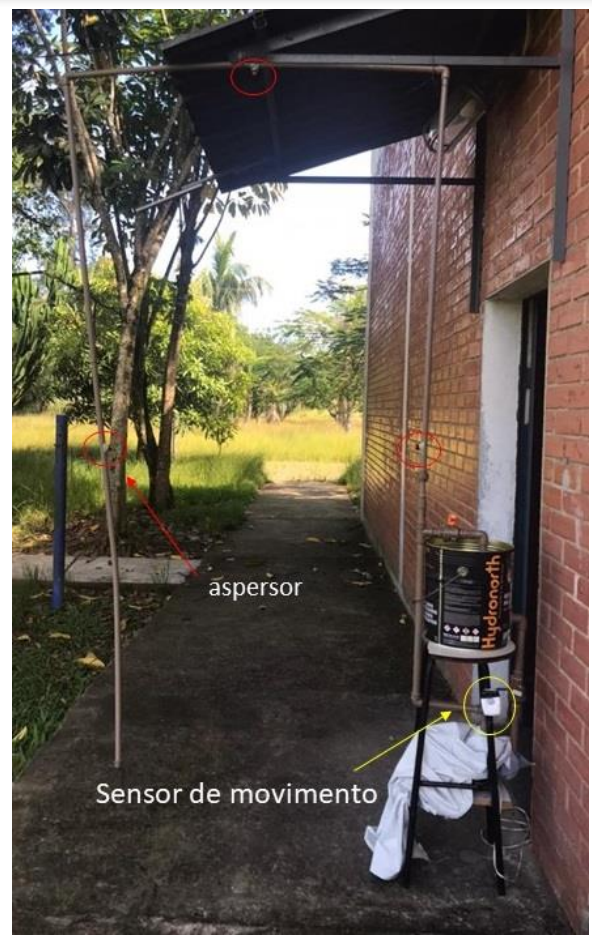

Fonte: O próprio autor (2021)

Para todos os trabalhos acima mencionados, foram desenvolvidos com material de apoio complementar como cartilhas, oficinas e análises de investimento e depreciação.

\section{RESULTADOS E DISCUSSÃO}

O seguinte projeto apresentado, mostrou ser capaz de inserir o aluno a realidade vivenciada, por meio de ações extensionistas as quais desenvolvem tanto o lado pessoal quanto o profissional. Esta imersão do aluno através de experiências, evidência o quanto a metodologia ativa incita o aluno mediante o método de sala invertida, desse modo o aluno ganha metas e responsabilidades no processo de construção de conhecimento.

$\mathrm{Na}$ figura 11, foi elaborado uma linha do tempo para demonstrar o desenvolvimento do projeto até 0 atual momento. Nela pode-se observar que mesmo devido a pandemia muitas ações extensionistas foram executadas, apesar de atividades presenciais estarem suspensas.

Figura 11 - Linha do tempo de realizações do projeto de extensão

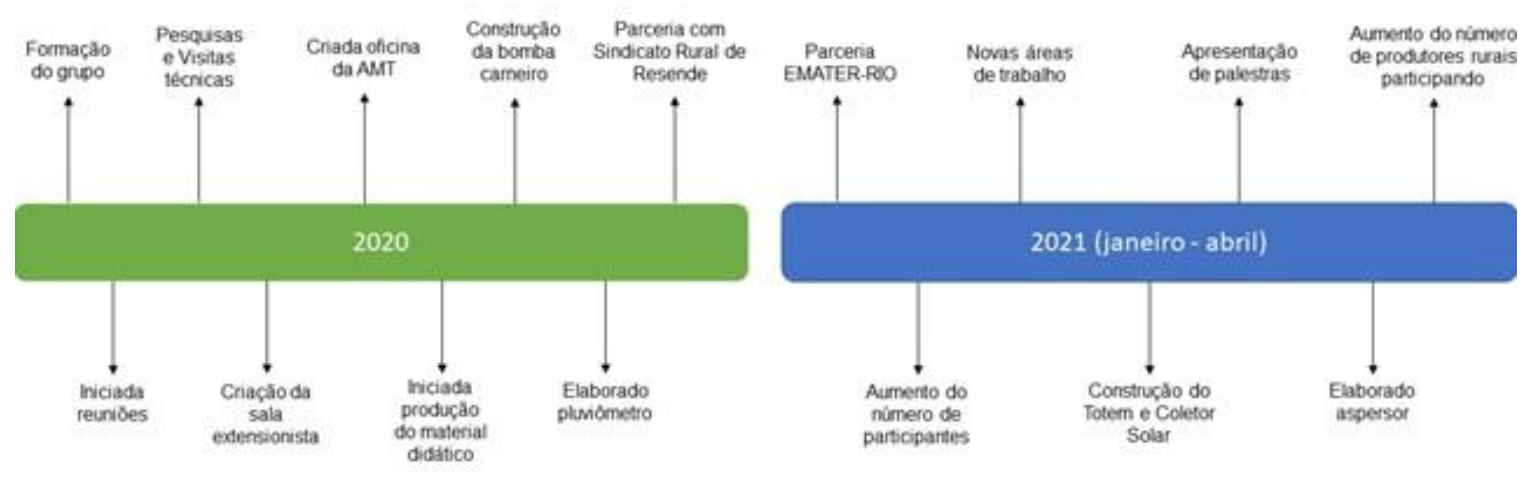

Fonte: O próprio autor (2021) 
Desde o início da formação, o grupo de participantes assumiu um dever com a sociedade em conectar os resultados das pesquisas e das necessidades verbalizadas nas reuniões com a adoção de conhecimentos e tecnologias pelos produtores rurais, desta forma, identificaram ser necessário a difusão de palestras, oficinas e cartilhas que orientem o agricultor para sua extensão de conhecimento. A criação de uma sala extensionista tornou-se necessária para a realização de tais práticas, como demonstrado na Figura 12, e somente poderão ser retomadas quando autorizadas pelo Governo do Estado/ Reitoria da Universidade devido a pandemia do Covid-19.

Figura 12 - Sala de ações extensionistas

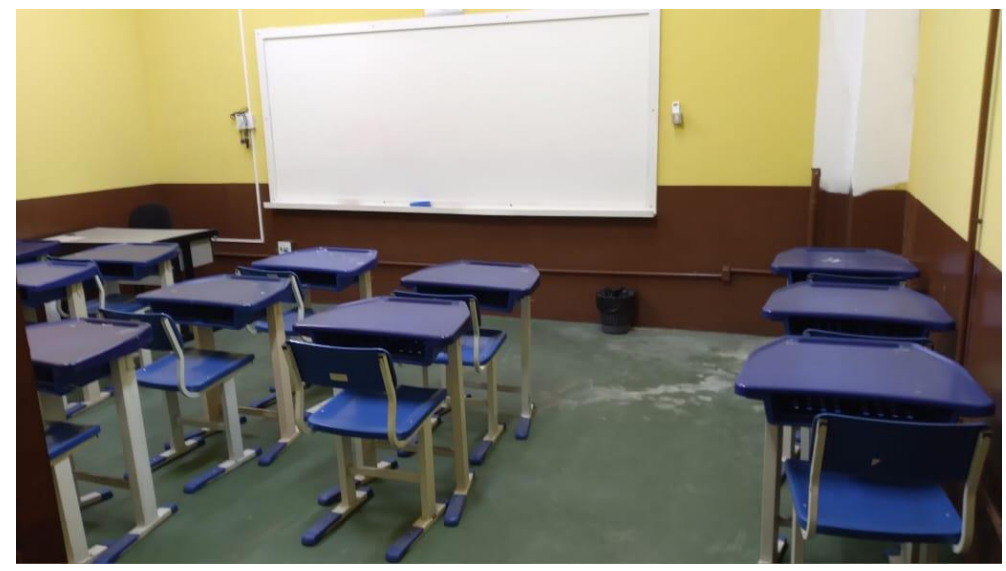

Fonte: O próprio autor (2021)

\section{CONCLUSÃO}

A imersão do aluno no meio extensionista, mostrou-se fundamental pois foi capaz de observar seu crescimento através das atividades atribuídas. Como um projeto com pouco tempo de atividades, observa-se a construção de caráter e profissionalismo nos alunos, as pesquisas destacaram o tamanho do potencial que os alunos podem desenvolver em diversos meios.

O uso da metodologia ativa e educação cognitiva que exploram nos alunos e orientadores um autodesenvolvimento, quando aplicada de forma correta é destacada como uma enorme ferramenta na condução da extensão, ainda mais pela pandemia do Covid-19 que agravou a necessidade de os integrantes formalizarem propostas para o grupo de forma acessível e que contribuíssem para o "pensamento fora da caixa". É perceptível que em alguns módulos de atuação o projeto tende a melhorar ao fim da pandemia, como comunicação e criatividade; e assim fortificar suas qualidades.

\section{Agradecimentos}

Os autores agradecem por todo apoio fornecido pela Universidade Estadual do Rio de Janeiro (UERJ), voluntários e orientadores do Projeto de Extensão "UERJ no Campo", ao Sindicato Rural de Resende e EMATER-RIO. Uma experiência com alto grau de aprendizagem que estimula e incentiva todos presentes, tanto no âmbito profissional quanto no social. Com um agradecimento especial a todos apoiadores do projeto, para seguirmos em mais um ano que proporcione frutos e vitórias.

\section{REFERÊNCIAS}


BRASIL - Ministério da Educação. Indissociabilidade ensino-pesquisa-extensão e a flexibilização curricular: uma visão da extensão. Fórum de Pró-Reitores de Extensão das Universidades Públicas Brasileiras e SESu/MEC. Porto Alegre: UFRGS. Brasília, p.23-24, 2006.

CASTRO SANTOS, Ana Manoela. Projeto de extensão universitária: um espaço propício para a formação do profissional de engenharia. COBENGE - Evento Online, Universidade de Ensino Superior de Feira de Santana, 2020.

EMATER-RIO. Bovinocultura - Pecuária de leite/ corte, 2019. Disponível em: http://www.emater.ri.gov.br/areaTecnica/BOVI2019.pdf. Acesso em: 30 março, 2021.

EMATER-RIO. Relatório de pequenos e médios animais ano 2019. Disponível em: http://www.emater.ri.gov.br/areaTecnica/PEQ2019.pdf. Acesso em: 30 março, 2021.

EMATER-RIO. Silvicultura Econômica 2019. Disponível em: http://www.emater.ri.gov.br/areaTecnica/SILVI2019.pdf. Acesso em: 30 março, 2021.

FONSECA, Régis. A estrutura do Instituto Central de Ciências: Aspectos históricos, científicos e tecnológicos de projeto, execução, intervenções e propostas de manutenção. Dissertação de Mestrado em Estruturas e Construção Civil, Publicação E.DM - 006 A/07, Departamento de Engenharia Civil e Ambiental, Universidade de Brasília, Brasília, DF, 203p., 2007.

PORTAL EDUCAÇÃO. Educação Cognitiva: do que se trata. Disponível em: https://siteantigo.portaleducacao.com.br/conteudo/artigos/direito/educacao-cognitiva-doque-se-trata/30088. Acesso em: 31 março, 2021.

SALLES CINTRA, Francisco. A extensão universitária e a promoção de competências na formação do aluno de engenharia. In: XLVII Congresso Brasileiro de Educação em Engenharia e II Simpósio Internacional de Educação em Engenharia da ABENGE, 2019, Fortaleza. Anais. Pontifícia Universidade Católica de Campinas - Faculdade de Engenharia Elétrica. Disponível em: http://www.abenge.org.br/cobenge/2019/anais.php. Acesso em : 31 março, 2021.

SILABE. Metodologia ativa: o que é, exemplos e suas diferenças. Disponível em: https://silabe.com.br/blog/metodologia-ativa-o-que-e-exemplos-e-suas-diferencas/. Acesso em: 07 abril, 2021.

SILVA, Ana Lúcia et al. A importância da Extensão Universitária na formação profissional: Projeto Canudos. Revista de enfermagem UFPE online. 2019.

\section{UERJ EXTENSION PROJECT IN THE FIELD: DEVELOPING THE RURAL ENVIRONMENT AND THE FORMATION OF THE ENGINEERING PROFESSIONAL}

Abstract: According to Coralina, "Happy is he who transfers what he knows and learns what he teaches"; that is, university extension contributes to the community in general by proposing that students and society interact and, in this way, there is an exchange of values between both. "In this sense, the relationship between teaching and extension leads to changes in the pedagogical process, to the extent that both constitute themselves 
as subjects of the same act: learning". (Brazil, 2006). UERJ, the University of the State of Rio de Janeiro, stimulates the participation of the faculty and students in various activities on all campuses, through incentives for events and stimulus to the development of social projects through the support of academic units and even student scholarships to students to carry out these activities. The proposal to be developed in this work, started before the CNE/2019, and reports the degree of satisfaction and maturity that the extension project "UERJ in the Field" has been bringing to teachers, students and volunteers, validating the potential that teaching, research and extension are complementary activities in academic, ethical and social development in preparing students for professional entry into society.

Keywords: UERJ in the field, extension, extensionist activity 